\title{
Sex and Regional Differences in the Incorporation of Neurons Born During Song Learning in Zebra Finches
}

\author{
E. J. Nordeen and K. W. Nordeen \\ Departments of Psychology and of Neurobiology and Anatomy, University of Rochester, Rochester, New York 14627
}

\begin{abstract}
In zebra finches only males sing, and several nuclei controlling song contain more neurons in adult males than in females. The ontogeny of sex differences in neuron number differs across song regions and overlaps with song learning in males. We examined the development of neuron number in several song regions in both sexes. We then determined whether neurons are born and incorporated into song nuclei as sex differences in neuron number emerge, and whether sex or regional differences in the insertion of such neurons may account for differences in the development of these areas. Males add neurons to hyperstriatum ventralis pars caudalis $(\mathrm{HVc})$ and Area $X$ between 20 and $55 \mathrm{~d}$ of age. In females there is no change in HVc neuron number during this time, and Area $X$ never appears as a distinct nucleus. In both sexes, ${ }^{3} \mathrm{H}$-thymidine administration between 20 and $30 \mathrm{~d}$ results in neuronal labeling at $55 \mathrm{~d}$ in $\mathrm{HVc}$ and the region of Area X. However, in these areas the incidence of labeled neurons is higher in males than in females. In contrast to HVc and Area X, sex differences in neuron number in the robustus nucleus of the archistriatum (RA) and the magnocellular nucleus of the neostriatum (MAN) emerge because males retain neurons that are lost in females between 20 and $55 \mathrm{~d}$ of age. Accordingly, RA and MAN neurons are not labeled following ${ }^{3} \mathrm{H}$-thymidine administration between 20 and $30 \mathrm{~d}$ of age. These data indicate that sex and regional differences in the ontogeny of song nuclei are related to differences in the incorporation of neurons born during song learning.
\end{abstract}

One way gonadal steroids establish sex differences in behavior is by controlling how many neurons are devoted to specific behaviors and physiological functions. Several areas of the adult vertebrate nervous system exhibit sex differences in neuron number that result from steroid actions exerted during sensitive periods in development (see Arnold and Gorski, 1984). In several cases, this sensitive period overlaps with naturally occurring neuron death, and one way that steroids create sex differences in neuron number is by preventing or attenuating the death of hormone-sensitive neurons (Breedlove, 1984; Nordeen et al., 1985). Yet, in most cases, the cellular mechanisms by which hormones influence neuron number are unknown. In addition to regulating neuron survival, steroids could influence neurogenesis, migration, or differentiation.

\footnotetext{
Received July 24, 1987; revised Dec. 15, 1987; accepted Dec. 17, 1987.

We are grateful to Marc Dorfman and Farida Sohrabji for their technical assistance. This work was supported by USPHS Grant HD22160 and an Alfred P. Sloan Fellowship to E.J.N.

Correspondence should be addressed to Ernest J. Nordeen at the above address. Copyright (c) 1988 Society for Neuroscience $0270-6474 / 88 / 082869-06 \$ 02.00 / 0$
}

Sex differences in neuron number are especially pronounced within neural regions controlling song learning and production in songbirds. In adult male zebra finches (Poephila guttata), gonadal androgens stimulate the production of a learned courtship song. Adult females do not normally sing, even if stimulated with androgen (Prove, 1974; Arnold, 1975a, b). In 2 regions essential for song production, the hyperstriatum ventralis pars caudalis $(\mathrm{HVc})$ and the robust nucleus of the archistriatum (RA), males have more neurons than do females (Nottebohm et al., 1976; Gurney, 1981; Nordeen and Nordeen, 1986). Sex differences in neuron number are also suspected in 2 other song areas, the magnocellular nucleus of the anterior neostriatum (MAN) and Area X, since both these regions are prominent in adult males but are reduced or unrecognizable in adult females (Nottebohm and Arnold, 1976). The MAN is critical for song learning (Bottjer et al., 1984), whereas the function of Area $X$ in song behavior is unknown. Male and female zebra finches also differ in the number of hormone-accumulating neurons within certain song control nuclei. In $\mathrm{HVc}$ and MAN, there are more neurons that selectively accumulate testosterone $(\mathrm{T})$ or its metabolite dihydrotestosterone (DHT) in males than in females (Arnold and Saltiel, 1979; Arnold, 1980). Thus, in zebra finches sex differences in neuron number underlie sex differences in both the anatomy and hormonal sensitivity of regions controlling song.

Several studies indicate that the gonadal hormone estradiol (E2) controls sex differences in neuron number and androgen accumulation within the song system. The song system is masculinized in females treated with E2 during the first few weeks after hatching and such E2-treated females sing in response to androgen stimulation (Gurney, 1981, 1982; Pohl-Apel and Sossinka, 1984; Nordeen et al., 1986, 1987). The ontogeny of song regions in males, E2-treated females and normal females indicates that there are important regional differences in the pattern and, perhaps, the mechanism by which E2 produces sex differences in neuron number and androgen accumulation. In RA, males and E2-treated females retain neurons that are lost in females during adolescence (Konishi and Akutagawa, 1985). Similarly, although both males and females lose neurons from MAN during adolescence, masculinization prevents the concurrent reduction in androgen target cell number that normally occurs in females (Bottjer et al., 1985; Bottjer, 1987; Nordeen et al., 1987). Thus, in both RA and MAN early E2 exposure may attenuate neuron death. In $\mathrm{HVc}$, however, E2 promotes neuronal addition during sexual differentiation. Both males and E2-treated females add neurons to this nucleus during adolescence (Bottjer et al., 1986a; Nordeen et al., 1987). Importantly, this increase in neuron number coincides with an equivalent increase in the number of androgen-accumulating $\mathrm{HVc}$ cells, 
suggesting that cells added to HVc in response to early E2 exposure are, or become, androgen-accumulating (Bottjer, 1987; Nordecn et al., 1987). Males also add ncurons to Area X during adolescence (Nordeen and Nordeen, 1986).

Since these changes in neuron number overlap with the period of song learning in males, understanding how these changes are produced may provide insight into the events that mediate this learning, as well as sexual differentiation. The sexually dimorphic addition of neurons to $\mathrm{HVc}$ and Area $\mathrm{X}$ may indicate that during adolescence masculinization increases either the migration or recruitment of existing neurons. On the other hand, neuronal addition in young males may reflect either enhanced production or survival of new neurons. It is well established that neurons continue to proliferate into adulthood in several songbird species (Goldman and Nottebohm, 1983; cf. Nottebohm, 1985) and are incorporated throughout a wide area of the telencephalon, including $\mathrm{HVc}$. The purpose of the present study was 3-fold: (1) to determine if neuronal addition to $\mathrm{HVc}$ and Area $X$ in males reflects ongoing neurogenesis, (2) to determine if regional differences in the ontogeny of neuron number correspond to differences in the incorporation of newly generated neurons, and (3) to determine if sex differences in the incorporation of neurons born during adolescence account for sex differences in neuron number that emerge during this period.

\section{Materials and Methods}

Beginning at $20 \mathrm{~d}$ after hatching, 4 zebra finches of each sex were injected intramuscularly with $2.5 \mu \mathrm{Ci} / \mathrm{gm}$ body weight of ${ }^{3} \mathrm{H}$-thymidine (New England Nuclear; specific activity, $25 \mathrm{Ci} / \mathrm{mmol}$ ) every $12 \mathrm{hr}$ for $10 \mathrm{~d}$. The juveniles were kept with their parents during this period. At $55 \mathrm{~d}$ of age, birds were sacrificed with an overdose of Equithesin and transcardially perfused with saline followed by buffered formalin. This survival time was chosen to insure that thymidine-labeled neurons had sufficient time to migrate and differentiate into identifiable neurons (see Nottebohm, 1985) and because we were interested in accounting for changes in neuron number that occur between 20 and $55 \mathrm{~d}$ of age. Brains were removed, postfixed in formalin for $2-4 \mathrm{~d}$, and embedded in paraffin. Serial coronal sections $(10 \mu \mathrm{m})$ were mounted onto microscope slides and then dipped in Kodak NTB-3 nuclear track emulsion. Autoradiograms were stored in desiccated dark containers at $4^{\circ} \mathrm{C}$ for 3-5 weeks. They were then developed (Kodak D19) and stained with thionin.

Total nuclear volume and neuron number were calculated for $\mathrm{HVc}$ and RA in both males and females, and for lateral MAN and Area X in males (in adult females, the boundaries of MAN are difficult to discern and $\Lambda$ rea $X$ is not visible in Nissl-stained material). Using a microprojector $(\times 40)$, the perimeter of each region was traced at regular intervals ranging from 10 to $120 \mu \mathrm{m}$, chosen to insure that at least 9 sections were sampled for each nucleus. Drawings were retraced onto a digitizing tablet interfaced to a computer that calculated their area (corrected for magnification). Using these areas, section thickness, and the intervals between samples, the total volume of each nucleus (left + right) was computed for each animal. Neuron density was determined by counting the number of neurons falling within a $125,440 \mu \mathrm{m}^{2}$ grid. Neurons were identified by their densely stained cytoplasm, pale nuclei, and large, round, darkly stained nucleoli. A minimum of 4 grids and 175 neurons was sampled for each nucleus. Total neuron number was estimated by multiplying total nuclear volume by neuronal density. A correction factor was not applied to these data since the nucleolus (the unit of count) is belicved to be displaced, rather than split in paraffin sections (Konigsmark, 1970).

The incidence of thymidine-labeled neurons was determined in RA and $\mathrm{HVC}$ of both males and females, and in Area X of males. Since in females Area $X$ is not visible in Nissl-stained sections, we analyzed a region of the lobus parolfactorius (LPO) that corresponds to the location of Area $\mathrm{X}$ in males and receives a projection from HVc neurons, as does the male Area $X$ (personal observations). In addition, an area immediately ventral to HVc and an area of LPO $500 \mu \mathrm{m}$ lateral to midline at the level of Area X was measured in both sexes. The incidence of labeled neurons in MAN was determined only in males. For each area, both left and right sides were sampled, and at least 150 neurons/ animal were analyzed. A neuron was considered labeled if the density of silver grains over the cell body exceeded $5 \times$ the density of grains over unstained neuropil (background). The densities of silver grains over both neurons and background were determined with the aid of an ocular grid. In the present case, the $5 \times$ background criterion for labeling was considered the most appropriate criterion for 2 reasons. First, we wanted to identify neurons born anytime between 20 and $55 \mathrm{~d}$ after hatching, not only those that had undergone their last division during thymidine administration. Second, since thymidine was administered repeatedly in this experiment, the heaviest labeled neurons could be derived from neuronal precursors that had incorporated thymidine on multiple occasions. In this case, the one-half maximum criterion would exclude neurons born during the period of interest but derived from precursors that had incorporated thymidine during only one division.

In order to assess changes in total neuron number between 20 and $55 \mathrm{~d}$ of age, 3 normal zebra finches of each sex were also sacrificed at $20 \mathrm{~d}$ of age. Their brains were embedded in paraffin, and serial coronal sections $(10 \mu \mathrm{m})$ were mounted onto microscope slides and stained with thionin. Total nuclear volume and cell number were calculated for $\mathrm{HVC}$ and RA in both males and females and for lateral MAN and Area X in males as described above.

Two-way analyses of variance and Student $t$ tests were used for all comparisons. Group differences were considered significant when they exceeded the $95 \%$ confidence level (2-tailed).

\section{Results}

Song regions differ in the pattern by which sex differences in neuron number develop. In HVc and Area X of males, marked neuronal addition occurs during adolescence, as shown in Table 1. Although the number of HVc neurons in males is already significantly greater than in females at $20 \mathrm{~d}$ of age $(t=3.72, d f$ $=6, p<0.01$ ), this sex difference is magnified between 20 and $55 \mathrm{~d}$ of age. During this period the number of neurons in $\mathrm{HVc}$ increases significantly in males, but not in females, as indicated by the significant interaction between sex and age $(F=7.99$, $d f$ $=1,12, p<0.02$ ). By day 55, the number of HVc neurons in males is over 3 times that in females. Males also add a significant number of neurons to Area $X$ between 20 and $55 \mathrm{~d}$ of age $(t=$ $3.29, d f=5, p<0.02$ ). This region was not apparent as a distinct nucleus within the LPO of females at either 20 or $55 \mathrm{~d}$.

In contrast to HVc and Area X, sex differences in RA and MAN arise through differential neuron loss. As shown in Table 1 , the number of RA neurons is significantly greater in males than in females across both age groups $(F=54.16, d f=1,10$, $p<0.001)$. This sex difference becomes larger during adolescence because females lose a small, but significant, number of RA neurons between 20 and $55 \mathrm{~d}$ of age $(t=2.19, d f=6, p<$ $0.05)$. In MAN, 20-d-old males and females do not differ in neuron number. At this age, MAN neurons are large, and the nucleus is easily drawn in both sexes. Although males lose a significant number of MAN neurons between 20 and $55 \mathrm{~d}(t=$ $6.8, d f=6, p<0.001$ ), the nucleus remains distinct from the surrounding neostriatum. During this same period, the female MAN also becomes smaller, although accurate measurements become impossible because the boundaries of the nucleus become indistinct. Thus, although it is our impression that neurons are also lost from MAN in females during adolescence, the magnitude of this loss cannot be quantified.

Extensive neuronal labeling is evident throughout the telencephalon in autoradiograms from males and females injected with ${ }^{3} \mathrm{H}$-thymidine between 20 and $30 \mathrm{~d}$ of age. The song regions analyzed differ markedly in their incorporation of neurons born during adolescence, and these differences are correlated with the regional differences in neuronal ontogeny noted above. In $\mathrm{HVc}$ and Area X-LPO, thymidine-labeled neurons are evident in 


\begin{tabular}{|c|c|c|c|}
\hline Nucleus & Volume $\left(\mathrm{mm}^{3}\right)$ & Neuron density & Neuron number \\
\hline \multicolumn{4}{|l|}{$\mathrm{HVc}$} \\
\hline \multicolumn{4}{|l|}{ Male } \\
\hline $20 \mathrm{~d}$ & $0.512 \pm 0.047$ & $0.117 \pm 0.003$ & $60,369 \pm 6394$ \\
\hline $55 \mathrm{~d}$ & $0.635 \pm 0.147$ & $0.178 \pm 0.041$ & $96,006 \pm 9412$ \\
\hline \multicolumn{4}{|l|}{ Female } \\
\hline $20 \mathrm{~d}$ & $0.181 \pm 0.026$ & $0.178 \pm 0.011$ & $31,695 \pm 4284$ \\
\hline $55 \mathrm{~d}$ & $0.089 \pm 0.047$ & $0.333 \pm 0.054$ & $24,360 \pm 9112$ \\
\hline \multicolumn{4}{|l|}{ Area X } \\
\hline \multicolumn{4}{|l|}{ Male } \\
\hline $20 \mathrm{~d}$ & $1.35 \pm 0.13$ & $0.236 \pm 0.004$ & $319,644 \pm 31,121$ \\
\hline $55 \mathrm{~d}$ & $1.94 \pm 0.35$ & $0.500 \pm 0.068$ & $857,603 \pm 190,190$ \\
\hline \multicolumn{4}{|l|}{ RA } \\
\hline \multicolumn{4}{|l|}{ Male } \\
\hline $20 d$ & $0.184 \pm 0.019$ & $0.177 \pm 0.010$ & $32,153 \pm 2172$ \\
\hline $55 \mathrm{~d}$ & $0.357 \pm 0.060$ & $0.092 \pm 0.018$ & $30,800 \pm 2029$ \\
\hline \multicolumn{4}{|l|}{ Female } \\
\hline $20 d$ & $0.129 \pm 0.008$ & $0.158 \pm 0.004$ & $20,172 \pm 817$ \\
\hline $55 \mathrm{~d}$ & $0.046 \pm 0.015$ & $0.392 \pm 0.074$ & $15,848 \pm 2059$ \\
\hline \multicolumn{4}{|l|}{ MAN } \\
\hline \multicolumn{4}{|l|}{ Male } \\
\hline $20 \mathrm{~d}$ & $0.761 \pm 0.064$ & $0.086 \pm 0.001$ & $65,539 \pm 5825$ \\
\hline $55 \mathrm{~d}$ & $0.230 \pm 0.051$ & $0.117 \pm 0.018$ & $24,509 \pm 1531$ \\
\hline Female, $20 \mathrm{~d}$ & $0.723 \pm 0.158$ & $0.076 \pm 0.077$ & $54,718 \pm 6763$ \\
\hline
\end{tabular}

Data shown (mean \pm SEM) are the total volume $(\mathrm{L}+\mathrm{R})$, density [neurons $/ \mu \mathrm{m}^{3}\left(\times 10^{3}\right)$ ], and estimated total number of neurons in HVc, RA, Area $\mathrm{X}$, and MAN at 20 and $55 \mathrm{~d}$ of age. Data on female MAN are shown only for $20 \mathrm{~d}$ since the boundaries of this nucleus cannot be reliably measured at $55 \mathrm{~d}$.

both males and females. Yet in RA of both sexes and in male MAN, the incidence of labeled neurons is negligible (male RA $=1.1 \pm 0.5 \%$, female $\mathrm{RA}=0.3 \pm 0.2 \%$, male $\mathrm{MAN}=0.8 \pm$ $0.3 \%$ ). Photomicrographs of autoradiograms depicting these regional differences in neuronal labeling in males are shown in Figure 1.

Although thymidine-labeled neurons are evident in $\mathrm{HVc}$ and Area X-LPO of both sexes, there are prominent sex differences in the incidence of these neurons (Fig. 2). In HVc, there is a significant sex $\times$ region (inside/outside) interaction in the incidence of labeled neurons $(F=17.98, d f=1,6, p<0.01)$. While such neurons are signiticantly more frequent in males than in females within HVc (males $=14.6 \pm 2.6 \%$; females $=$ $6.1 \pm 1.7 \%),{ }^{1}$ just under $\mathrm{HVc}$ there is no sex difference in the incidence of neurons born during adolescence (males $=6.3 \pm$ $1.2 \%$; females $=8.2 \pm 1.7 \%$ ). Similarly, in the region of Area $\mathrm{X}$-LPO, the percentage of thymidine-labeled neurons is greater in males than in females, yet the incidence of neuronal labeling just outside of this region does not differ significantly between

\footnotetext{
The probability of detecting a ${ }^{3} \mathrm{H}$-thymidine-labeled cell will depend on the distance between that cell's nucleus and the emulsion. Since large nuclei are more likely than small nuclei to be close to the emulsion, sex differences in nuclear size could contribute to sex differences in neuronal labeling. The diameter of ncuronal nuclei in $\mathrm{HVc}$ was larger in males than in females. Using the approach and assumptions outlined by Arnold et al. (1976) we calculated, for both males and females, the probability that a labeled cell would be detected. Given that the nucleolus was our unit of count, this probability is equal to $(z+r) / t$, where $z$ is the average distance traveled by a beta particle through brain tissue, $r$ is the nuclear radius, and $t$ the section thickness. When this formula is applied to our data, the incidence of labeled $\mathrm{HVc}$ neurons remains significantly greater in males $(25.8 \%)$ than in females $(12.8 \%)$. We chose not to present these corrected data since the assumptions inherent in the formula cannot be verified (see Arnold, 1981). In the region of Area X-LPO, average nuclear diameter does not differ significantly between males and females.
}

the sexes (sex $\times$ region (inside/outside) interaction, $F=6.6, d f$ $=1,6, p<0.05$ ). In this area just outside of Area X-LPO the incidence of labeled neurons is $7.2 \pm 1.2 \%$ for males and 6.4 $\pm 2.3 \%$ for females.

\section{Discussion}

We have shown that male zebra finches add neurons to both $\mathrm{HVC}_{\mathrm{c}}$ and Area $\mathrm{X}$ during the period of song learning. This neuronal addition reflects the insertion of newly born neurons into these regions. Moreover, sex differences in the production or persistence of these neurons contribute to the sexual differentiation of these 2 nuclei. In female zebra finches (which do not develop song), there is no increase in $\mathrm{HVc}$ neuron number during adolescence, and Area $\mathrm{X}$ fails to emerge as a distinct nucleus. Correspondingly, although some new neurons are incorporated into these regions in young females, by $55 \mathrm{~d}$ of age the frequency and number of these neurons is far less than in males.

Although neurons born during adolescence are distributed widely throughout the telencephalon, their incidence varies markedly among song regions. For instance, neither MAN nor RA neurons are labeled following ${ }^{3} \mathrm{H}$-thymidine administration between 20 and $30 \mathrm{~d}$ of age. This corresponds to the lack of neuronal addition to these nuclei in either juvenile males or females. Sex differences in MAN and RA probably occur through the differential loss of neurons born before day 20 . Because sex and regional differences in the incidence of neuronal labeling correspond so closely to the extent of neuron addition during adolescence, we feel confident that this labeling does indeed reflect neurogenesis rather than, for instance, DNA damage and repair.

Sex differences in either neurogenesis or neuron survival could 


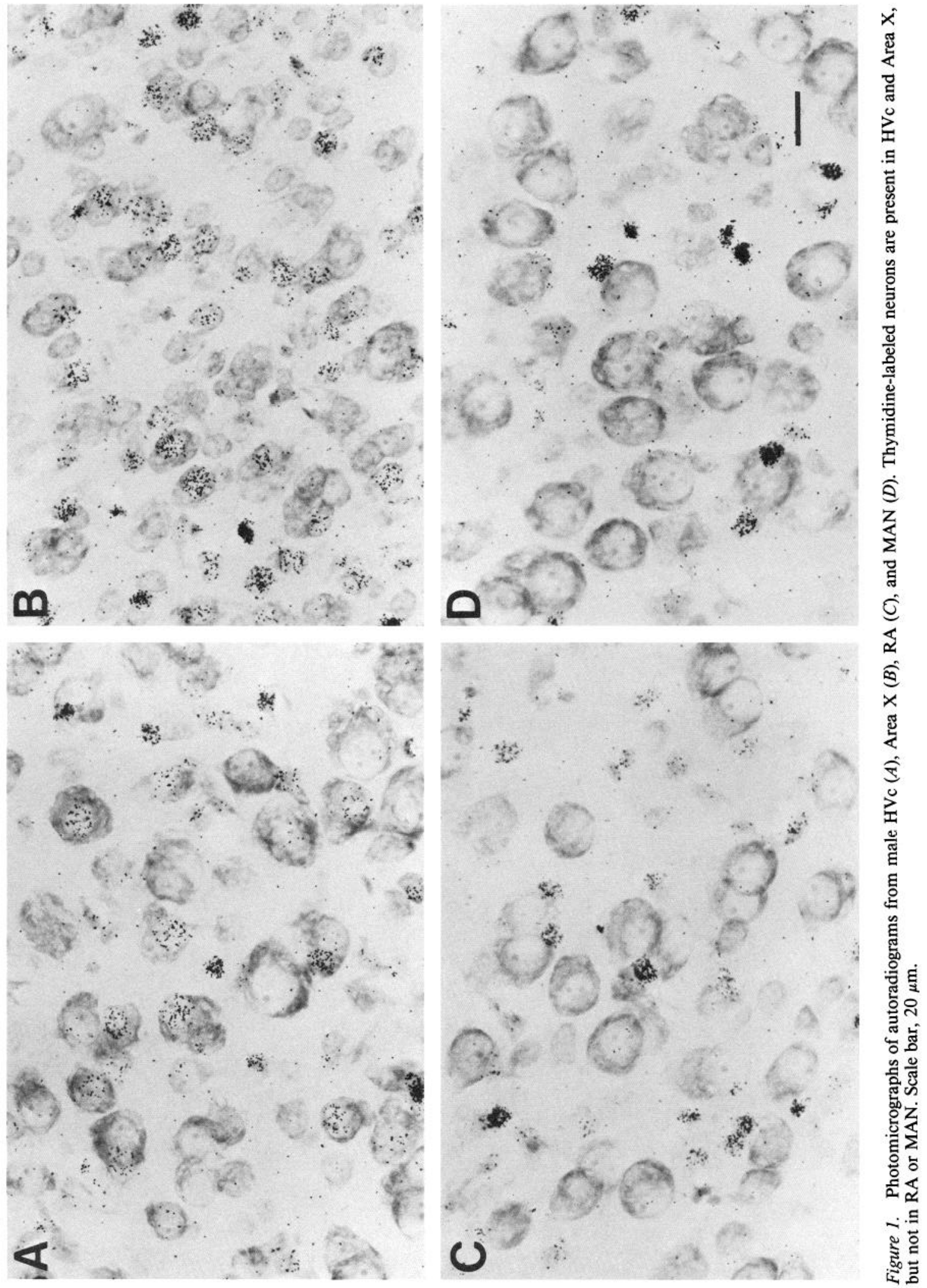


account for the incidence of thymidine-labeled neurons in HVc and Area $X$ being greater in males than in females. For instance, juvenile males may insert either more or additional types of neurons into these regions than do females. Alternatively, fewer newly born neurons may die in males than in females between 20 and $55 \mathrm{~d}$ of age. In fact, the rate of cell death in HVc is lower in males than in females at 19 and $25 \mathrm{~d}$ after hatching (Kirn and DeVoogd, 1985). Whereas in young females the production and insertion of new neurons is apparently offset by cell death, it may be that in males increased survival of newly generated neurons promotes an overall increase in neuron number. In order to understand how hormones regulate sexual differentiation within the song system, it will be important to distinguish between the differential neurogenesis and cell death hypotheses. We cannot yet do so, since our analyses were done $25 \mathrm{~d}$ after ${ }^{3} \mathrm{H}$-thymidine administration. Further studies to elaborate the time course over which sex differences in newly generated cells emerge in HVc and Area $\mathrm{X}$ may resolve this issue.

An important question is how the sexually dimorphic addition of neurons to HVc and Area X relates to the development of other sex differences within the song system. For instance, the number of androgen-accumulating cells in $\mathrm{HVC}_{\mathrm{C}}$ is greater in adult males than in females. In both adolescent males (Bottjer, 1987) and E2-treated females (Nordeen et al., 1987), the number of these androgen target cells increases in parallel with neuronal addition to HVc. This suggests that neurons born and inserted into $\mathrm{HVc}$ during this period are, or become, androgen-accumulating cells. Although we do not yet have direct evidence of this, it is an attractive possibility since it implies that sex differences in the incorporation of newly born neurons into $\mathrm{HVc}$ mediate the sexual differentiation of both neuronal number and androgen sensitivity within this nucleus.

Neurons added to HVc or Area X during adolescence may also contribute to the development of sex differences in the afferent or efferent connections of these nuclei. For example, although few HVc neurons labeled by thymidine administered during adolescence project to Area $\mathrm{X}$, many do project to RA (Nordeen and Nordeen, 1988). In males, RA is massively invaded by $\mathrm{HVc}$ axons between 25 and $35 \mathrm{~d}$ of age (Konishi and Akutagawa, 1985). This innervation is absent or sparse in females. Thus, it seems likely that sex differences in either the production or survival of neurons born during adolescence create sex differences in this neural pathway. The sexual differentiation of this projection may also contribute to the development of sex differences in RA neuron number (Konishi and Akutagawa, 1985). However, our data indicate that sex differences in RA neuron number precede the sexually dimorphic innervation of RA.

Anothcr important issue is the relationship between neuronal addition to the song system and song learning. Interestingly, neuron addition in $\mathrm{HVc}$ is also correlated with song learning in adult canaries. Canaries replenish HVc neurons yearly (Nottebohm, 1985) and are able to incorporate new syllables into their song annually (Nottebohm and Nottebohm, 1978). As in zebra finches, this neuronal addition likely reflects ongoing neurogenesis as injections of ${ }^{3} \mathrm{H}$-thymidine in adult canaries consistently label a population of interneurons within HVc (Goldman and Nottebohm, 1983; Paton and Nottebohm, 1984; Paton et al., 1985). It is probable that in canaries, as in zebra finches, gonadal hormones regulate the addition of neurons to HVc. Seasonal changes in canary $\mathrm{HVc}$ volume and neuron number correlate with seasonal fluctuations in androgen level (Nottebohm, 1981,

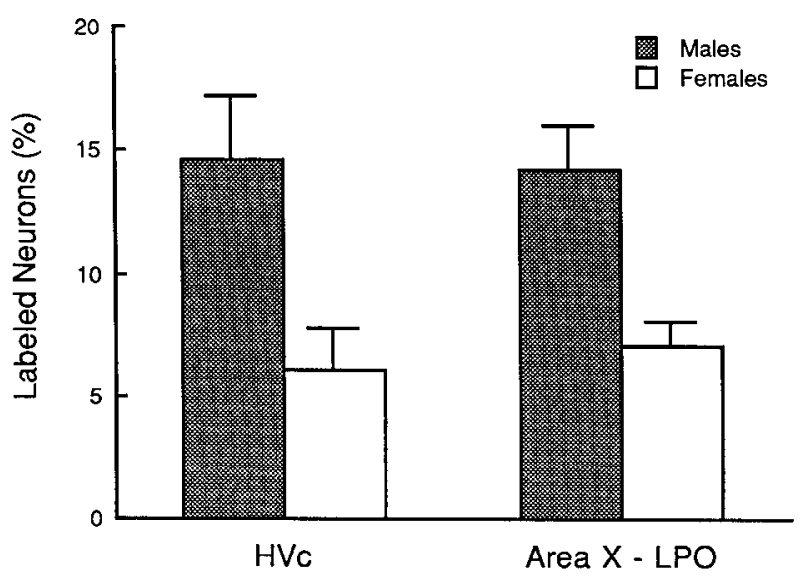

Figure 2. Histograms showing the percentage of thymidine-labeled cells in HVc and Area X-LPO of males and females. Bars represent means \pm SEM. Males have a significantly greater percentage of labeled cells than females in both HVc and the region of the LPO that corresponds to Area $\mathrm{X}$ in males.

1985). Although both adult male and female canaries incorporate new neurons into HVc (Goldman and Nottebohm, 1983), it is not yet known if seasonal neuron addition to canary $\mathrm{HVc}$ is sexually dimorphic. If so, sex differences in the production or survival of HVc neurons may appear at only certain times of the year and account for seasonal neuron addition in males.

There are 2 key issues that need to be addressed experimentally to appreciate how developmental changes in the song system relate to vocal development. First, it is important to know if the patterns of neuronal loss and addition in the developing song system occur even in the absence of song learning. If so, these changes in neuron number may merely produce the substrate necessary for vocal development, with more subtle neural changes, i.e., increases in dendritic length and synapse number (DeVoogd and Nottebohm, 1981; DeVoogd et al., 1985), actually storing the experiences of song learning. On the other hand, memorization of a song model and/or vocal practice may facilitate or fashion the changes in neuronal number that occur during adolescence. In adult female canaries, for instance, disrupting song learning through deafening attenuates the androgen-induced increase in $\mathrm{HVc}$ volume and neuron number that normally accompanies song development (Bottjer et al., 1986b; Bottjer and Dignan, 1988). The second issue is whether neuron loss and addition in the song system are related more closely to sensory or sensorimotor learning. Unfortunately, studies of neural development in male zebra finches do not address this issue since these 2 phases of song learning overlap in this species (Immelmann, 1969). In other species (i.e., song sparrows and swamp sparrows), sensory and sensorimotor learning are well separated (see Marler, 1987). Characterizing neural development in such species may help us to understand how the insertion of new neurons and the loss of others contribute to distinct stages in song development.

\section{References}

Arnold, A. P. (1975a) The effects of castration on song development in zebra finches (Poephila guttata). J. Exp. Zool. 191: 261-278.

Arnold, A. P. (1975b) The effects of castration and androgen replacement on song, courtship, and aggression in zebra finches (Poephila guttata). J. Exp. Zool. 191: 309-326.

Arnold, A. P. (1980) Quantitative analysis of sex differences in hor- 
monc accumulation in the zebra finch brain: Methodological and theoretical issues. J. Comp. Neurol. 189: 421-436.

Arnold, A. P. (1981) Quantitative analysis of steroid autoradiograms. J. Histochem. Cytochem. 29: 207-211.

Arnold, A. P., and R. A. Gorski (1984) Gonadal steroid induction of structural sex differences in the central nervous system. Annu. Rev. Neurosci. 7: 413-442.

Arnold, A. P., and A. Saltiel (1979) Sexual difference in pattern of hormone accumulation in the brain of a song bird. Science 205: 702705.

Arnold, A. P., F. Nottebohm, and D. W. Pfaff (1976) Hormone concentrating cells in vocal control and other areas of the brain of the zebra finch (Poephila guttata). J. Comp. Neurol. 165: 487-512.

Bottjer, S. W. (1987) Ontogenetic changes in the pattern of androgen accumulation in song-control nuclei of male zebra finches. J. Neurobiol. 18: 125-139.

Bottjer, S. W., and T. P. Dignan (1988) Joint hormonal and sensory stimulation modulate neuron number in adult canary brain. J. Neurobiology (in press).

Bottjer, S. W., E. A. Miesner, and A. P. Arnold (1984) Forebrain lesions disrupt development but not maintenance of song in passerine birds. Science 224: 901-903.

Bottjer, S. W., S. L. Glaessner, and A. P. Arnold (1985) Ontogeny of brain nuclei controlling song learning and behavior in zebra finches. J. Neurosci. 5: 1556-1562.

Bottjer, S. W., E. A. Miesner, and A. P. Arnold (1986a) Changes in neuronal number, density and size account for increases in volume of song-control nuclei during song development in zebra finches. Neurosci. Lett. 67: 263-268.

Bottjer, S. W., J. N. Schoonmaker, and A. P. Arnold (1986b) Auditory and hormonal stimulation interact to produce neural growth in adult canaries. J. Neurobiol. 17: 605-612.

Breedlove, S. M. (1984) Androgen forms sexually dimorphic spinal nucleus by saving motoneurons from programmed death. Soc. Neurosci. Abstr. 10: 927.

DeVoogd, T., and F. Nottebohm (1981) Gonadal hormones induce dendritic growth in the adult avian brain. Science 214: 202-204.

DeVoogd, T. J., B. Nixdorf, and F. Nottebohm (1985) Synaptogenesis and changes in synaptic morphology related to acquisition of a new behavior. Brain Res. 329: 304-308.

Goldman, S., and F. Nottebohm (1983) Neuronal production, migration, and differentiation in a vocal control nucleus of the adult female canary brain. Proc. Natl. Acad. Sci. USA 80: 2390-2394.

Gurney, M. (1981) Hormonal control of cell form and number in the zebra finch song system. J. Neurosci. 1: 658-673.

Gurney, M. (1982) Behavioral correlates of sexual differentiation in the zebra finch song system. Brain Res. 231: 153-172.

Immelmann, K. (1969) Song development in the zebra finch and other estrildid finches. In Bird Vocalizations, R. A. Hinde, ed., Cambridge University Press, New York.

Kirn, J. R., and T. J. DeVoogd (1985) Direct evidence that male and female cell death rates differ in the developing zebra finch song system. Soc. Neurosci. Abstr. 11: 532.
Konigsmark, B. W. (1970) Methods for the counting of neurons. In Contemporary Research Methods in Neuroanatomy, W. J. H. Nauta and S. O. E. Ebbesson, eds., Springer-Verlag, New York.

Konishi, M., and E. Akutagawa (1985) Neuronal growth, atrophy, and death in a sexually dimorphic song nucleus in zebra finches. Nature 315: 145-147.

Marler, P. (1987) Sensitive periods and the roles of specific and general sensory sțimulation in birdsong learning. In Imprinting and Cortical Plasticity, J. P. Rauschecker and P. Marler, eds., Wiley, New York.

Nordeen, K. W., and E. J. Nordeen (1986) Sex differences in the songbird brain involve neurons born during adolescence. Soc. Neurosci. Abstr. 12: 1214.

Nordeen, K. W., and E. J. Nordeen (1988) Projection neurons within a vocal motor pathway are born during song learning in zebra finches. Nature (in press).

Nordeen, E. J., K. W. Nordeen, D. R. Sengelaub, and A. P. Arnold (1985) Androgens prevent normally occurring cell death in a sexually dimorphic spinal nucleus. Science 229: 671-673.

Nordeen, K. W., E. J. Nordeen, and A. P. Arnold (1986) Estrogen establishes sex differences in androgen accumulation in zebra finch brain. J. Neurosci. 6: 734-738.

Nordeen, E. J., K. W. Nordeen, and A. P. Arnold (1987) Sexual differentiation of androgen accumulation within the zebra finch brain through selective cell loss and addition. J. Comp. Neurol. 259: 393399.

Nottebohm, F. (1981) A brain for all seasons: Cyclical anatomical changes in song control nuclei of the canary brain. Science $214: 1368$ 1370 .

Nottebohrn, F. (1984) Birdsong as a model in which to study brain processes related to learning. Condor 86: 227-236.

Nottebohm, F. (1985) Neuronal replacement in adulthood. In Hope for a New Neurology, F. Nottebohm, ed, pp. 143-161, New York Academy of Science, New York.

Nottebohm, F., and A. Arnold (1976) Sexual dimorphism in vocal control areas of the song bird brain. Science 194: 211-213.

Nottebohm, F., and M. E. Nottebohm (1978) Relationship between song repertoire and age in the canary, Serinus canarius. Z. Tierpsychol. 46: 298-305.

Nottebohm, F., T. M. Stokes, and C. M. Leonard (1976) Central control of song in the canary (Scrinus canarius). J. Comp. Neurol. 165: $457-486$.

Paton, J. A., and F. Nottebohm (1984) Neurons generated in the adult brain are recruited into functional circuits. Science 225: 1046-1048.

Paton, J. A., B. E. O'Loughlin, and F. Nottebohm (1985) Cells born in adult canary forebrain are local interneurons. J. Neurosci. 5: 30883093.

Pohl-Apel, G., and R. Sossinka (1984) Hormonal determination of song capacity in females of the zebra finch: Critical phase of treatment. Z. Tierpsychol. 64: 330-336.

Pröve, E. (1974) Der Einfluss von Kastration und Testosteronsubstitution auf das Sexualverhalten mannlicher Zebrafinken (Taeniopygia guttata castanotis Gould). J. Ornithol. 115: 338-347. 